\title{
Modelling Phosphorus Removal in Horizontal Subsurface Flow Constructed Wetlands
}

\author{
Longhua Gao and Long Xie
}

\begin{abstract}
In this paper a mathematical model for prediction of phosphorus removal with total phosphorus (TP) as the check index in horizontal subsurface flow constructed wetlands was developed. The model considered the water flow and transportation, diffusion, dispersion and biochemical reaction of phosphorus. The physical and biochemical parameters of the model were calibrated by one set of the experimental data. Then the model was valided by another set of the experimental data. The predicted effluent TP concentrations were well agreed with the actual effluent TP concentrations. The model can be used to simulate the phosphorus removal effect in horizontal subsurface flow constructed wetlands. The average removal rate of TP for domestic sewage in planted and unplanted constructed wetland with high concentration of influent were $\mathbf{8 8 . 2 2} \%$ and $85.06 \%$ respectively, while their removal rates were $94.23 \%$ and $90.77 \%$ respectively with low concentration of influent. So vegetation had improvement effect on TP removal.
\end{abstract}

Index Terms-Horizontal subsurface flow constructed wetlands, mathematical model, numerical method, phosphorus removal

\section{INTRODUCTION}

Constructed wetlands (CWs) are designed and built to optimize the physical, chemical and biological processes of natural wetlands in treating wastewater. CWs have been used for primary, secondary and tertiary treatment of municipal or domestic wastewater [1], mine drainage [2], agricultural runoff [3] and landfill leachate [4], et al. Previous studies demonstrated that CWs have high treatment efficiency, low cost and strong ability of shock loading resistance systems.

Design criteria and analysis methods for CWs have evolved from relationships derived from a technical database quantifying nutrient removal to advanced models. The early design approach was based on empirical equtions derived only from the relationgship between input and output nutrient levels. Rencent advance models are useful tools for explaning the complexity of hydraulics in substrate coupled with many processes involved in contaminant removal, such as Monod kinetics model [5] and ecosystem model [6]. However, model complexity does not produce proportional insight into the factors affecting contaminant removal due to the difficulty of estimating a large number of parameters inherent in contaminant removal process. There is the need to conduct studies on CWs to improve understanding of the system internal factors affecting contaminant removal processes and enhance predictive ability of models.

Among CWs, horizontal subsurface flow constructed wetland (HSFCW) is a widely used concept. Wastewater

Manuscript received May 16, 2013, revised July 2, 2013.

L. H. Gao and L. Xie are with Pearl River Water Research Institute, Guangzhou 510611, China (e-mail: cyxlong@163.com). flows horizontally through the artificial filter bed, usually consisting of a substrate of sand or gravel and the helophyte roots and rhizomes. The advantages of HSFCWs include a lower susceptibility to surface weather extremes due to the moderating thermal capacity of the gravel and surrounding soil, decreased risk of pathogen exposure, and fewer vector and odor problems.

The main objectives of this paper were to develop a mathematical model for prediction of phosphorus removal with TP as the check index in HSFCWs, and to provide a tool for CWs design.

\section{MATERIALS AND METHODS}

\section{A. Experimental Setup}

The research was conducted at Hohai University, Nanjing, China. Two experimental HSFCWs used in this study (named $\mathrm{A}$ and B) consisted of plastic containers $(1.5 \mathrm{~m}$ long, $0.5 \mathrm{~m}$ wide and $0.8 \mathrm{~m}$ high, Fig. 1) first filled with cinder $(0.35 \mathrm{~m}$ high), then with natural sand $(0.4 \mathrm{~m})$. The inlet zone and outlet zone $(0.15 \mathrm{~m}$ long $)$ set a perforated plate respectively to avoid surface flow, and filled with gravel $(0.75 \mathrm{~m}$ high). The water level was kept $0.05 \mathrm{~m}$ under the natural sand surface to set a water depth of $0.7 \mathrm{~m}$. The $\mathrm{CW}$ A planted Arundo donax var.versicolor, and CW B did not plant. Two concentration of synthetic domestic sewage (Table I) were delivered to the two CWs continuously at a rate of approximately $0.042 \mathrm{~m}^{3} / \mathrm{d}$ to yield a hydraulic retention time (HRT) of $5 \mathrm{~d}$.

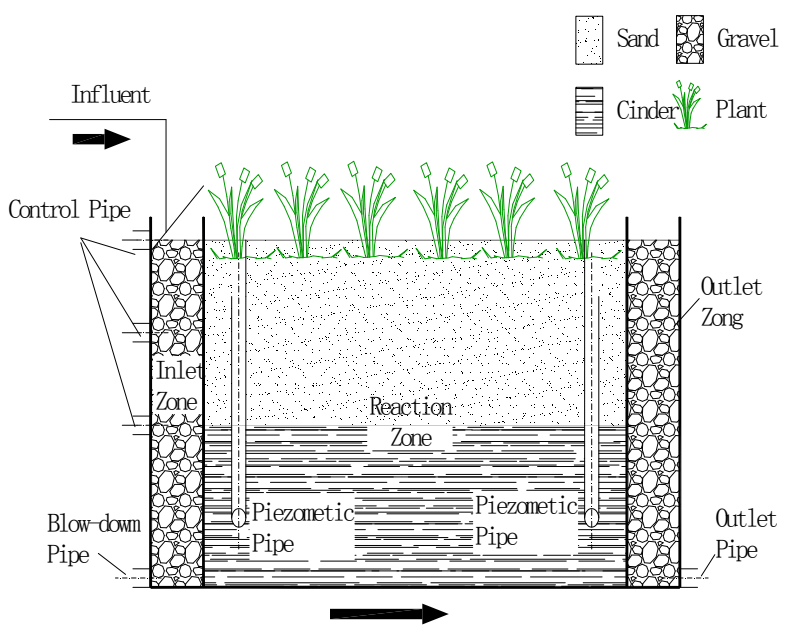

Fig. 1. The schematic diagram of experimental equipment

TABLE I: INFLUENT QUALITY

\begin{tabular}{cccccc}
\hline \hline Influent & $\mathrm{pH}$ & $\mathrm{TP}(\mathrm{mg} / \mathrm{L})$ & $\mathrm{TN}(\mathrm{mg} / \mathrm{L})$ & $\mathrm{NH}_{4}{ }^{+}-\mathrm{N}(\mathrm{mg} / \mathrm{L})$ & $\mathrm{TP}(\mathrm{mg} / \mathrm{L})$ \\
\hline High & $6.73-7.08$ & $51.49-58.35$ & $16.94-19.14$ & $15.04-17.37$ & $1.31-1.38$ \\
Low & $6.66-7.11$ & $24.16-44.81$ & $7.82-9.47$ & $6.75-8.61$ & $0.58-0.69$ \\
\hline \hline
\end{tabular}




\section{B. Sample Collection and Monitoring}

The operation and monitoring of the two CWs were conducted from June to December 2006 and 2007. Five water quality indices, TP, TN, TP, pH and DO, were measured on the influent and on the effluent from each of the $\mathrm{CW}$. The physical properties and the adsorption characters of the substrates were also measured for the need of numerical simulation. Water quality analysis were conducted in accordance with the methods described in Standard Method [7]. The treatment efficiency was determined using the averaged influent and effluent concentrations of the above major water quality parameters.

\section{Mathematical Model}

The Phosphorus removal model of HSFCWs has two governing equations. One equation is the flow equation, which describes the head distribution and flow rate in the HSFCWs. The second is the phosphorus transport and transformation equation, which describes the phosphorus concentration within the flow system.

A number of assumptions have been made in the development of the model. These assumptions are summarized below :

1. Flow is considered two-dimensional.

2. Darcy's law is valid.

3. Porosity and hydraulic conductivity are constant with time, and porosity is uniform in space.

4. Gradients of fluid density, viscosity, and temperature do not affect the velocity distribution.

5. Fluid and aquifer properties are not affected by the reactions that occur.

\section{1) Flow equation}

A general form of the equation describing the transient flow of an imcompressible fluid in a heterogeneous anisotropic aquifer may be derived by combining Darcy's Law with the continuity equation. A general two-dimensional flow equation may be written in Cartesian coordinates as:

$$
S \frac{\partial H}{\partial t}=\frac{\partial}{\partial x}\left(W \frac{\partial H}{\partial x}\right)+\frac{\partial}{\partial y}\left(W \frac{\partial H}{\partial y}\right)-\varepsilon
$$

Where $S$ is the storage coefficient (dimensionless), $H$ is hydraulic head (L), $t$ is time (T), $W$ is the transmissibility coefficient $\left(\mathrm{L}^{2} \mathrm{~T}^{-1}\right), \varepsilon$ is the source fluid flux (positive for outflow, negative for inflow) expressed as volumetric flux per unit area $\left(\mathrm{LT}^{-1}\right)$, and $x$ and $y$ are Cartesian coordinates (L).

By Darcy's Law, the average linear flow velocity is given by:

$$
\begin{aligned}
& V_{x}=-\frac{k_{x x}}{\eta} \frac{\partial H}{\partial x} \\
& V_{y}=-\frac{k_{y y}}{\eta} \frac{\partial H}{\partial y}
\end{aligned}
$$

where $k_{x x}, k_{y y}$ is the hydraulic conductivity along the $x, y$ coordinate axes $\left(\mathrm{LT}^{-1}\right)$, and $\eta$ is the effective porosity (dimensionless).

\section{2) Phosphorus transport and transformation equation}

Phosphorus is removed in CWs by substrate adsorption and desorption, plant uptake, biological uptake and release [8]. The two-dimensional phosphorus transport and transformation equation is:

$$
\begin{gathered}
R \frac{\partial C}{\partial t}=\frac{\partial}{\partial x}\left(D_{x x} \frac{\partial C}{\partial x}\right)+\frac{\partial}{\partial x}\left(D_{x y} \frac{\partial C}{\partial y}\right)+\frac{\partial}{\partial y}\left(D_{y x} \frac{\partial C}{\partial x}\right)+\frac{\partial}{\partial y}\left(D_{y y} \frac{\partial C}{\partial y}\right) \\
-V_{x} \frac{\partial C}{\partial x}-V_{y} \frac{\partial C}{\partial y}+\frac{\varepsilon\left(C-C^{\prime}\right)}{\eta b}-R \theta^{i-20} \lambda C+\sum_{n=1}^{m} B_{n} \\
\sum_{n=1}^{3} B_{n}=-r_{b}-r_{p}+r_{S}
\end{gathered}
$$

where $C$ is the concentration of phosphorus $\left(\mathrm{ML}^{-3}\right), C^{\prime}$ is the concentration of phosphorus in the source fluid $\left(\mathrm{ML}^{-3}\right), R$ is the retardation factor (dimensionless), $b$ is the aquifer thickness $(\mathrm{L}), t^{\prime}$ is the temperature $\left({ }^{\circ} \mathrm{C}\right), D$ is the dispersion tensor $\left(\mathrm{L}^{2} \mathrm{~T}^{-1}\right), \theta$ is the temperature correction factor (dimensionless), $\lambda$ is the substrate adsorption rate constant $\left(\mathrm{T}^{-1}\right)$ for phosphorus, $B_{n}$ is the all reaction rate term of phosphorus $\left(\mathrm{ML}^{-3} \mathrm{~T}^{-1}\right), r_{b}$ is the biological uptake rate $\left(\mathrm{ML}^{-3} \mathrm{~T}^{-1}\right), r_{p}$ is the plant uptake rate $\left(\mathrm{ML}^{-3} \mathrm{~T}^{-1}\right)$ and $r_{s}$ is the phosphorus release rate $\left(\mathrm{ML}^{-3} \mathrm{~T}^{-1}\right)$,

A general dispersion tensor equation may be written as:

$$
\begin{aligned}
& D_{x x}=\frac{\left(\alpha_{L} V_{x}^{2}+\alpha_{T} V_{y}^{2}\right)}{|V|}+D_{m} \\
& D_{y y}=\frac{\left(\alpha_{L} V_{y}^{2}+\alpha_{T} V_{x}^{2}\right)}{|V|}+D_{m} \\
& D_{x y}=D_{y x}=\left(\alpha_{L}-\alpha_{T}\right) \frac{V_{x} V_{y}}{|V|}
\end{aligned}
$$

where $\alpha_{L}$ and $\alpha_{T}$ is the longitudinal and transverse dispersivities (L), $D_{m}$ is the molecular diffusion $\left(\mathrm{L}^{2} \mathrm{~T}^{-1}\right)$.

\section{Numerical Methods}

The discretization uses a rectangular, uniformly spaced, block-centered, finite-difference grid. Implicit finite-difference method are used to solve the (1). The average linear flow velocities are then calculated and used to solve the phosphorus transport and transformation (4) using the method of characteristics and particle tracking [9].

\section{1) Flow equation}

In the uniform isotropic substrate, the implicit difference scheme for flow equation is

$$
\frac{L}{T} \frac{H_{l, m}^{k+1}-H_{l, m}^{k}}{\Delta t}=\frac{H_{l-1, m}^{k+1}+H_{l+1, m}^{k+1}-2 H_{l, m}^{k+1}}{\Delta x^{2}}+\frac{H_{l, m-1}^{k+1}+H_{l, m+1}^{k+1}-2 H_{l, m}^{k+1}}{\Delta y^{2}}-\frac{\varepsilon_{l, m}}{T}(9)
$$

all the same items above equationg are merged, then:

$\frac{H_{l-1, m}^{k+1}+H_{l+1, m}^{k+1}}{\Delta x^{2}}+\frac{H_{l, m-1}^{k+1}+H_{l, m+1}^{k+1}}{\Delta y^{2}}-\left(\frac{2}{\Delta x^{2}}+\frac{2}{\Delta y^{2}}+\frac{L}{T \Delta}\right) H_{l, m}^{k+1}=\frac{L}{T \Delta t} H_{l, m}^{k}+\frac{\varepsilon_{l, m}}{T}$

the strong implicit procedure (SIP) is adopted for solution of the discretized equation.

\section{2) Phosphorus transport and transformation equation}

We used the method of characteristics to solve the 
phosphorus transport and transformation equation by introducing a set of moving particles that can be traced within the stationary coordinates of a finite-difference grid.

Equation (4) can be rearranged to obtain:

$\frac{\partial C}{\partial t}=\frac{1}{R}\left(D_{l m} \frac{\partial C}{\partial x_{m}}\right)-\frac{V_{l}}{R} \frac{\partial C}{\partial x_{l}}+\frac{\varepsilon_{l, m}(C-C)}{R \eta b}-\theta^{-20} \lambda C+\sum B \quad l, m=x, y$

Equation (11) describes the change in concentration over time at fixed reference points within a stationary coordinate system, which is referred to as an Eulerian framework. An alternative perspective is to consider changes in concentration over time in representative fluid parcels as they move with the flow of the fluid past fixed points in space. This is a moving coordinate system, which is referred to as a Lagrangian framework. We convert (11) from an Eulerian framework to a Lagrangian one through the material derivative.

$$
\frac{d C}{d t}=\frac{\partial C}{\partial t}+\frac{\partial C}{\partial x} \frac{d x}{d t}+\frac{\partial C}{\partial y} \frac{d y}{d t}
$$

The last two terms on the right side include the material derivatives of position, which are defined by the velocity in the $\mathrm{x}$ - and $\mathrm{y}$ - directions.

$$
\begin{aligned}
& \frac{d x}{d t}=\frac{V_{x}}{R} \\
& \frac{d y}{d t}=\frac{V_{y}}{R}
\end{aligned}
$$

Substituting (11), (13) and (14) into (12) gives:

$\frac{d C}{d t}=\frac{1}{R} \frac{\partial}{\partial x_{l}}\left(D_{l m} \frac{\partial C}{\partial x_{m}}\right)+\frac{\varepsilon_{l, m}(C-C)}{R \eta b}-\theta^{\prime-20} \lambda C+\sum B \quad l, m=x, y$

The solutions of the system of equations comprising (13)-(15) may be given as $x=x(t), y=y(t)$, and $C=C(t)$, and are called the characteristic curves of (12). Given solutions to (13)-(15), a solution to the original partial differential equation may be obtained by following the characteristic curves.

\section{RESULTS AND DISCUSSIONS}

\section{A. Experimental Results}

As shown in Fig. 2, the average removal rate of TP for domestic sewage in planted $\mathrm{CW}$ and unplanted $\mathrm{CW}$ with high concentration of influent were $88.22 \%$ and $85.06 \%$ respectively, while their removal rates were $94.23 \%$ and $90.77 \%$ respectively with low concentration of influent. The planted constructed wetland showed a little well performance than unplanted, so vegetation had improvement effect on TP removal. It has been suggested that plant rhizosphere enhances microbial density and activity by providing root surface for microbial growth, a source of carbon compounds through root exudates and a micro-aerobic environment via root oxygen release [10].
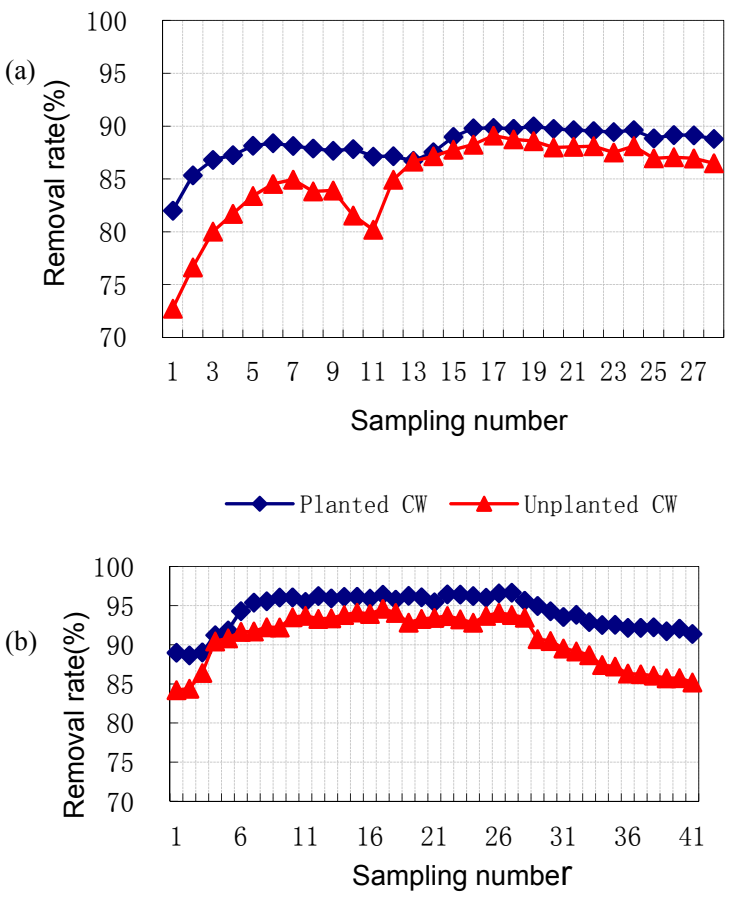

$\longrightarrow$ Planted $\mathrm{CW} \longrightarrow$ Unplanted $\mathrm{CW}$

Fig. 2. Removal rate of TP in HSFCWs: (a) high influent concentration (b) low influent concentration

\section{B. Model Calibration}

To evaluate model performance, model output of hydraulic head, flow field, and TP concentration were compared to experimental data. Parameters were adjusted to fit model output to experimental data.

Table II described the physical parameters of substrate. The biochemical parameters of the modle were calibrated by the experimental data in 2006 (Table III). The calibration results of effluent of TP were showed in Fig. 3.
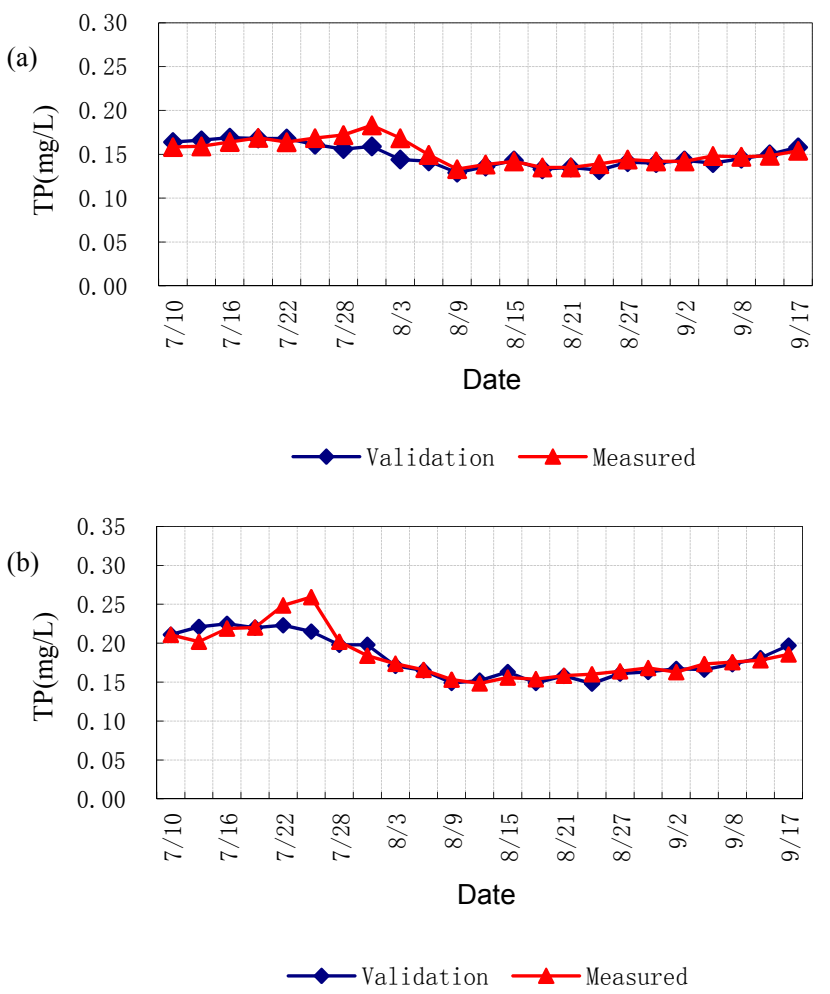

Fig. 3. TP calibration results in HSFCWs: (a) planted CW (b) unplanted CW 
TABLE II: PhySICAL PARAMETERS OF SUBSTRATE

\begin{tabular}{|c|c|c|c|c|c|}
\hline$\rho_{d}\left(\mathrm{~kg} / \mathrm{m}^{3}\right)$ & $\eta$ & $K_{x x}^{A}(\mathrm{~m} / \mathrm{d})$ & $K_{z z}^{A}(\mathrm{~m} / \mathrm{d})$ & $b(\mathrm{~m})$ & $\omega(\%)$ \\
\hline 1587.0 & 0.38 & 13.6 & 13.6 & 0.7 & 6.11 \\
\hline
\end{tabular}

TABLE III: BIOCHEMICAL PARAMETERS OF HSFCWS

\begin{tabular}{|c|c|c|c|c|c|}
\hline \hline HSFCWs & $\begin{array}{c}\lambda \\
(1 / \mathrm{d})\end{array}$ & $\theta_{i}$ & $\begin{array}{c}r_{b} \\
\left(\mathrm{mg} \cdot \mathrm{m}^{-3} \cdot \mathrm{d}^{-1}\right)\end{array}$ & $\begin{array}{c}r_{p} \\
\left(\mathrm{mg} \cdot \mathrm{m}^{-3} \cdot \mathrm{d}^{-1}\right)\end{array}$ & $\begin{array}{c}r_{s} \\
\left(\mathrm{mg} \cdot \mathrm{m}^{-3} \cdot \mathrm{d}^{-1}\right)\end{array}$ \\
\hline Planted & 0.544 & 1.01 & 65.23 & 17.89 & 26.88 \\
\hline Unplanted & 0.479 & 1.02 & 55.13 & 0 & 3.21 \\
\hline
\end{tabular}

\section{Model Validation}

The model validation was performed using the experimental data in 2007 and calibrated parameters (Table II and Table III). From the graph of predicted versus actual TP outflow (Fig. 4), it can be seen that the average perdicted efflunet and measured efflunent TP of planted $\mathrm{CW}$ were $0.034 \mathrm{mg} / \mathrm{L}$ and $0.037 \mathrm{mg} / \mathrm{L}$ respectively, while their efflunent $\mathrm{TP}$ were $0.057 \mathrm{mg} / \mathrm{L}$ and $0.059 \mathrm{mg} / \mathrm{L}$ respectively in unplanted $\mathrm{CW}$. Also, a Wilcoxon signed rank test revealed that perdicted effluent concentrations for TP is similar to those of the measured values (Table IV). Therefor, the model can be used to simulate the phosphorus removal effect in HSFCWs.

TABLE IV: WILCOXON SIGN RANK TEST

\begin{tabular}{|c|c|c|}
\hline HSFCWs & $p$ values & $\mathrm{H}_{0}$ \\
\hline Planted & 0.728 & Fail to reject \\
\hline Unplanted & 0.409 & Fail to reject \\
\hline
\end{tabular}

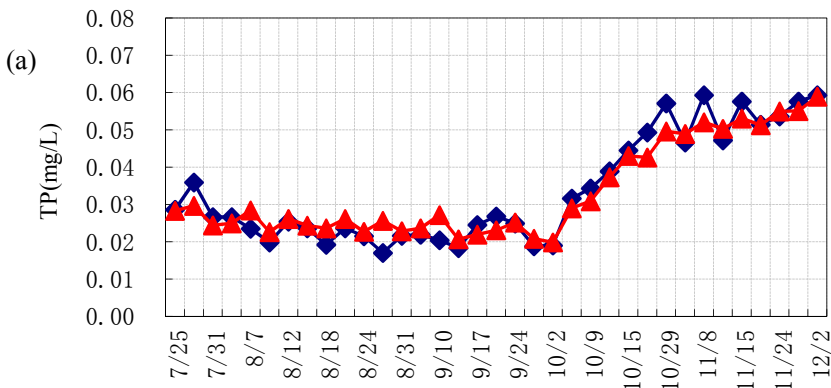

Date

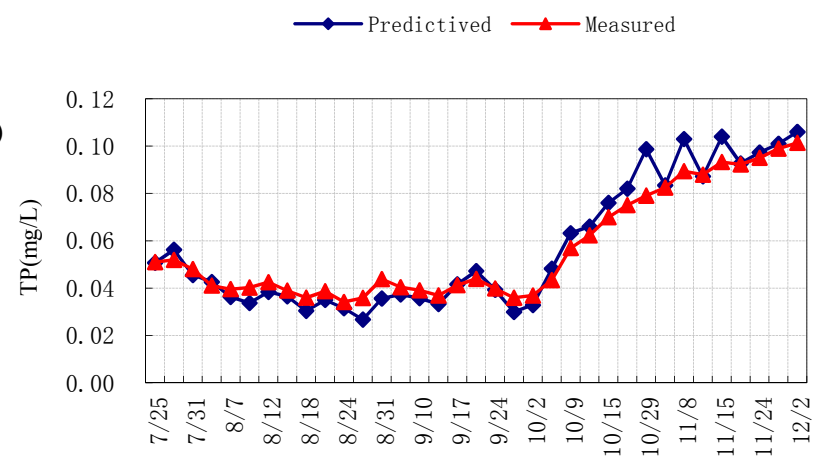

Date

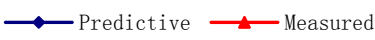

Fig. 4. Predicted effluent and measured effluent TP concentrations of HSFCWs: (a) planted CW (b) unplanted CW

\section{CONCLUSIONS}

This study developed an phosphorus removal model according to the features of the HSFCWs. The model considered the water flow and transportation, diffusion, dispersion and biochemical reaction of the phosphorus. Simulation results from the model agreed well with the results from the experiments. The difference between computed and measured removal rate was less than $5 \%$. This indicted that the developed model, the calibrated physical and biochemical parameters were rational. The model can be used to simulate the phosphorus removal effect in HSFCWs.

\section{REFERENCES}

[1] J. Chang, S. Wu, Y. Dai, W. Liang, and Z. Wu, "Treatment performance of integrated vertical-flow constructed wetland plots for domestic wastewater," Ecological Engineering, vol. 44, pp. 152-159, 2012.

[2] S. Ji, S. Kim, and J. Ko, "The status of the passive treatment systems for acid mine drainage in South Korea," Environ Geol, vol. 55, pp. 1181-1194, 2008.

[3] H. L. Tyler, M. T. Moore, and M. A. Locke, "Potential for phosphate mitigation from agricultural runoff by three aquatic macrophytes," Water Air Soil Pollut, vol. 223, pp. 4557-4564, 2012.

[4] A. Białowiec, L. Davies, A. Albuquerque, and P. F. Randerson, "The influence of plants on nitrogen removal from landfill leachate in discontinuous batch shallow constructed wetland with recirculating subsurface horizontal flow," Ecological Engineering, vol. 40, pp. 44-52, 2012.

[5] E. Llorens, J. Obradors, and M. T. Alarcón-Herrera, "Modelling the non-biogenic steps of arsenic retention in horizontal subsurface flow constructed wetlands," Chemical Engineering Journal, vol. 223, pp. 657-664, 2013.

[6] X. F. Xu, H. Q. Tian, Z. J. Pan, and C. R. Thomas, "Modeling ecosystem responses to prescribed fires in a phosphorus-enriched Everglades wetland: II. Phosphorus dynamics and community shift in response to hydrological and seasonal scenarios," Ecological Modelling, vol. 222, pp. 3942-3956, 2011.

[7] SEPA, Monitoring and Analysis Method of Water and Wastewater, 4st ed. Beijing, China: China Environmental Science Press, 2002.

[8] B. C. Braskerud, "Factors affecting phosphorus retention in small constructed wetlands treating agricultural non-point source pollution," Ecological Engineering, vol. 19, pp. 41-61, 2002.

[9] A. O. Grader, D. W. Peaceman, and A. G. Pozzi, "Numerical calculation of multidimensional miscible displacement by the method of characteristics," Society of Petroleum Engineers Journal, vol. 4, no. 1, pp. 26-36, 1964.

[10] H. Brix, "Do macrophytes play a role in constructed treatment wetlands," Water Science and Technology, vol. 35, no. 5, pp. 11-17, 1997.

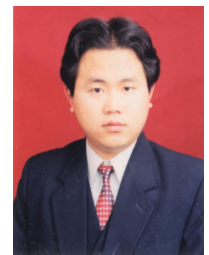

Longhua Gao was born in Chongqing China, 1975. He graduated from Hohai University with a $\mathrm{PhD}$ in hydrology and water resources, 2006.

He has been working for Pearl River Water Research Institute in Guangzhou China after graduation. He is a Senior Engineer currently. His research interests mainly focus on ecological water treatment. He has published 18 journal papers and 8 conference papers.

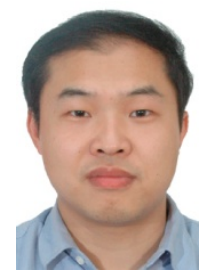

Long Xie was born in Zunyi China, 1982. He graduated from Hohai University with a $\mathrm{PhD}$ in environmental engineering, 2010.

He has been working for Pearl River Water Research Institute in Guangzhou China after graduation. He is an Engineer currently. His research interests mainly focus on water environmental treatment. He has published 6 journal papers and 2 conference papers. 